\title{
SATISFAÇÃO COM A PROFISSÃO: UM ESTUDO COM PROFESSO- RES DE EDUCAÇÃO FÍSICA
}

\author{
Ivan Bremm de Oliveira \\ Universidade Federal de Pelotas, Pelotas, Rio Grande do Sul, Brasil \\ José Antonio Bicca Ribeiro \\ Universidade Federal de Pelotas, Pelotas, Rio Grande do Sul, Brasil \\ Mariangela da Rosa Afonso \\ Universidade Federal de Pelotas, Pelotas, Rio Grande do Sul, Brasil
}

\begin{abstract}
Resumo
O trabalho objetivou verificar a satisfação profissional dos professores de EF da Rede Federal de Ensino na cidade de Pelotas - RS. Trata-se de um estudo de caso descritivo que utilizou um questionário relativo à satisfação com a profissão e o perfil docente. Participou do estudo a totalidade dos professores de EF $(n=20)$. Nas categorias Exercício da Profissão e Trabalho Pedagógico, foram encontrados níveis elevados de satisfação, com mais de $90 \%$ dos professores mostrando-se satisfeitos com a profissão. As trocas estabelecidas com os alunos, o reconhecimento por parte deles e a realização profissional foram os principais motivos para tal. Fatores externos como a baixa valorização e o pouco reconhecimento pelos pares ou gestão institucional foram razões para a insatisfação dos professores.
\end{abstract}

Palavras-chave: Professores. Educação Física. Satisfação no emprego.

\section{Introdução}

Ao longo dos anos, a satisfação no trabalho tem sido tema de inúmeros estudos nas mais diversas áreas (MARTINEZ; PARAGUAY, 2003; MARQUEZE; MORENO, 2005; SECO, 2005). Relata-se que, desde a década de 1930, pesquisas com esta temática começaram a ser desenvolvidas (KLIJN, 1998). Porém, investigações relativas à satisfação docente são mais recentes, a partir da década de 1970 (PEDRO; PEIXOTO, 2006). E, a partir da década de 1980, surgem os primeiros estudos com indicadores acerca da satisfação/insatisfação de trabalhadores da área da educação (NÓVOA, 1991).

No que tange à satisfação no trabalho, ela pode ser analisada sob diferentes aspectos: como sinônimo de motivação, de atitude, de satisfação versus insatisfação no trabalho ou como um estado emocional (MARTINEZ; PARAGUAY, 2003).

Além disso, a satisfação no trabalho é um dos aspectos geradores de saúde. Já a insatisfação pode acarretar danos físicos, mentais e sociais, ocasionando problemas na vida pessoal e no ambiente organizacional (MARQUEZE; MORENO, 2005). No âmbito escolar, a insatisfação no trabalho docente contribui decisivamente para o abandono do exercício do magis- 
tério, que muitas vezes ocorre de forma lenta, influenciado por fatores pessoais e institucionais (BUENO; LAPO, 2003).

Sobre a profissão docente, já em 1981 a Organização Internacional do Trabalho (OIT) a considerava como "uma profissão de risco físico e mental" (OIT, 1981, p. 15-16). Desta forma, possíveis fatores que possam influenciar a satisfação no trabalho docente devem constituir uma preocupação constante em pesquisas.

Em suma, podemos dizer que a satisfação no trabalho é a soma dos diferentes sentimentos que o trabalhador manifesta em relação a sua atividade laboral. Para este estudo, tal satisfação será caracterizada como os sentimentos relatados pelos professores de EF da Rede Federal de Educação Profissional, Ciência e Tecnologia (RFEPCT) de Pelotas - RS em relação aos diferentes elementos relacionados ao exercício da profissão docente e ao trabalho pedagógico.

No âmbito da Educação Física (EF) escolar, estudos sobre os sentimentos de satisfação e insatisfação de professores (SILVA; KRUG, 2007; RIGHETO, 2009; MOREIRA, 2010; JUSTINO, 2011; FERREIRA, 2011), síndrome de Burnout com professores de EF (SINOTT et al., 2014; SANTINI; MOLINA NETO, 2005), qualidade de vida de professores (ACIOLY, 2005; LEMOS; NASCIMENTO; BORGATTO, 2007; FARIAS et al.; 2008; PEREIRA; TEIXEIRA; LOPES, 2013; MOREIRA et al., 2012; BOTH; NASCIMENTO; BORGATTO, 2008; COLARES et al., 2015) têm pautado a discussão sobre a temática do trabalho docente e a satisfação profissional.

Ao analisarmos esses estudos, notamos que eles foram realizados com base na prática de professores das redes de ensino municipal, estadual ou particular da Educação Básica, buscando estabelecer relações entre o trabalho desempenhado por eles na sala de aula e as nuances e interfaces que tal trabalho proporciona aos docentes. Em contraponto, pesquisas tendo como objeto de estudo os docentes da RFEPCT, tratando especificamente dos professores da área de EF, constituem uma minoria. Nesses trabalhos, buscaram compreender a formação e a prática pedagógica dos professores dessa rede de ensino (AZEVEDO, 2001; AZEVEDO; PEREIRA; SÁ, 2011). Do mesmo modo, no que tange o ensino superior, a maioria dos estudos se refere à qualidade de vida no ambiente de trabalho (CATAPAN et al., 2014), avaliação do estresse ocupacional e desenvolvimento da síndrome de Burnout (GOMES et al., 2013) ou ainda a satisfação profissional e sua relação com a saúde docente (BORGES; SIMÕES, 2012). Ou seja, a discussão da literatura pauta-se pela compreensão do ambiente de trabalho e suas interfaces com relação à saúde dos docentes.

No que concerne à rede de ensino objeto deste estudo, a Lei Federal n ${ }^{\circ} 11.892$, de 29 de dezembro de 2008, instituiu, no âmbito do sistema federal de ensino, a RFEPCT e criou os Institutos Federais de Educação, Ciência e Tecnologia, vinculados ao Ministério da Educação. No entanto, a história do ensino técnico no Brasil teve início em 1909, com a criação de 19 escolas de aprendizes e artífices (MEIRELES, 2007).

Na cidade campo desta pesquisa, a história da RFEPCT teve início em 1917, concomitante ao aniversário da cidade de Pelotas, onde ocorreu a assembleia de fundação da Escola de Artes e Officios (MEIRELES, 2007), hoje campus Pelotas do Instituto Federal de Educação, Ciência e Tecnologia Sul-rio-grandense (IF-Sul), contando com 35 cursos em funcionamento. O outro campus que compõe a RFEPCT na cidade de Pelotas, campus Pelotas - Visconde da Graça, teve como origem o Conjunto Agrotécnico Visconde da Graça e passou a integrar a RFEPCT pela Portaria no 715 de 2010 do Ministério da Educação, publicada no Diário Oficial da União de 2 de junho de 2010 e retificada no Diário Oficial da União de 17 de junho de 2010, com 26 cursos.

Por considerarmos a profissão docente como de relevância social, e pela RFEPCT vivenciar a maior fase de expansão de sua história (TAVARES, 2012), com o aumento tanto do número de professores, mas, também de alunos, pois, segundo Schwartzman e Castro (2013), 
14,2\% dos estudantes brasileiros encontram-se em cursos profissionais e técnicos de nível médio, estudos acerca da satisfação profissional de seus docentes em diferentes dimensões (infraestrutura, remuneração, jornada de trabalho, expectativas futuras, dentre outras) tornamse necessárias, estabelecendo um panorama sobre a área.

Esperamos, assim, que este estudo permita o conhecimento dos fatores que possam influenciar a satisfação do trabalho dos professores de EF desta rede de ensino, contribuindo para o avanço dos estudos desta temática e relacionando os resultados com as investigações existentes até o momento, além de apontar diretrizes norteadoras para políticas que venham melhorar a qualidade de vida e a satisfação profissional desse grupo estudado.

Diante do exposto, o presente trabalho objetivou verificar a satisfação profissional dos professores de EF da RFEPCT na cidade de Pelotas - RS e investigou os possíveis fatores que contribuem para esta satisfação/insatisfação, bem como o perfil sociodemográfico dos professores de EF dessa rede de ensino.

\section{Procedimentos metodológicos}

Para este estudo, optou-se por uma ênfase na abordagem de cunho qualitativa e, em relação aos objetivos, por uma metodologia de cunho descritiva, pois, segundo Gil (2002, p. 42):

As pesquisas descritivas têm como objetivo primordial descrever as características de determinadas populações ou fenômenos. Uma de suas peculiaridades está na utilização de técnicas padronizadas de coleta de dados, tais como o questionário e a observação sistemática.

Considerando os procedimentos técnicos utilizados, esta pesquisa insere-se em um estudo de caso, uma vez que, "entre os tipos de pesquisa qualitativa característicos, talvez o estudo de caso seja um dos mais relevantes" (TRIVIÑOS, 1987, p. 133).

Em relação aos colaboradores deste estudo, participou dele a totalidade dos professores de EF que compõem a RFEPCT $(\mathrm{n}=20)$ na cidade de Pelotas - RS, constituída pelo campus Pelotas (16 docentes) e pelo campus Visconde da Graça (quatro docentes) do IFSUL.

No que se refere aos aspectos éticos, esta pesquisa foi aprovada pelo Comitê de Ética e Pesquisa da Universidade Federal de Pelotas, sob o Parecer $n^{\circ} 793.810 /$. Foi encaminhada às instituições uma carta de apresentação e de autorização, com vistas à realização do estudo. Além disso, todos os participantes deste estudo foram convidados a participar voluntariamente e assinaram o Termo de Consentimento Livre e Esclarecido. Para garantir o anonimato das identidades, foram tratados por Professor A, Professor B, de forma subsequente até perfazer o total de entrevistados. Após a autorização dos diretores de ensino e dos coordenadores da área de EF dos respectivos campi, deu-se início à coleta de dados, que ocorreu durante o mês de outubro de 2014.

Para a coleta de dados, foi utilizado um questionário dividido em duas partes: a) perfil docente, para a identificação das características sociodemográficas, e b) satisfação docente, relacionado com os indicadores de satisfação na categoria Exercício da Profissão e na categoria Trabalho Pedagógico, adaptado de Justino (2011). Nas questões fechadas, os participantes escolheram entre os seguintes indicadores de satisfação: Plenamente satisfeito; Satisfeito; Razoavelmente satisfeito; Pouco satisfeito e Insatisfeito e, nas questões abertas, os professores responderam livremente.

Após coletadas as informações, os dados obtidos através das questões de múltipla escolha foram tabulados, apresentados segundo frequências absoluta (n) e relativa (\%) e analisados através da estatística descritiva (THOMAS; NELSON; SILVERMAN, 2007). As ques- 
tões abertas caracterizadas como descritivas foram analisadas, categorizadas e discutidas a partir da análise de conteúdo de Bardin (2011).

\section{Resultados e discussões}

Os dados referentes ao perfil sociodemográfico dos professores de EF da RFEPCT, na cidade de Pelotas - RS, estão apresentados na Tabela 1, assim como as informações referentes à formação e ao trabalho desempenhado nas instituições estudadas.

Tabela 1. Características sociodemográficas da população estudada

\begin{tabular}{|c|c|c|}
\hline Variáveis $(\mathbf{n = 2 0})$ & $\mathbf{N}$ & $\%$ \\
\hline \multicolumn{3}{|l|}{ Gênero } \\
\hline Masculino & 13 & 65,0 \\
\hline Feminino & 7 & 35,0 \\
\hline \multicolumn{3}{|l|}{ Idade (anos) } \\
\hline Até 29 & 3 & 15,0 \\
\hline $30-39$ & 6 & 30,0 \\
\hline $40-49$ & 3 & 15,0 \\
\hline$\geq 50$ & 8 & 40,0 \\
\hline \multicolumn{3}{|l|}{ Naturalidade } \\
\hline Pelotas & 11 & 55,0 \\
\hline Outra & 9 & 45,0 \\
\hline \multicolumn{3}{|l|}{ Estado civil } \\
\hline Casado & 15 & 75,0 \\
\hline Outros & 5 & 25,0 \\
\hline \multicolumn{3}{|l|}{ Campus } \\
\hline Pelotas & 16 & 80,0 \\
\hline Visconde da Graça & 4 & 20,0 \\
\hline \multicolumn{3}{|l|}{ Tipo de vínculo e C. H. ${ }^{1}$} \\
\hline Efetivo (40h DE) & 17 & 85,0 \\
\hline Temporário/substituto (40h) & 3 & 15,0 \\
\hline \multicolumn{3}{|l|}{ Função atual } \\
\hline Docente & 18 & 90,0 \\
\hline Docente e administrativa & 2 & 10,0 \\
\hline \multicolumn{3}{|l|}{ Instituição Formação Inicial } \\
\hline Pública & 17 & 85,0 \\
\hline Privada & 3 & 15,0 \\
\hline \multicolumn{3}{|l|}{ Titulação } \\
\hline Especialista & 9 & 45,0 \\
\hline Mestre & 9 & 45,0 \\
\hline Doutor & 2 & 10,0 \\
\hline \multicolumn{3}{|l|}{ Tempo de serviço no IFSUL } \\
\hline Até 4 anos & 11 & 55,0 \\
\hline 5 a 12 anos & 2 & 10,0 \\
\hline 13 anos ou mais & 7 & 35,0 \\
\hline
\end{tabular}

${ }^{1}$ Todos os professores efetivos têm carga horária de 40h com dedicação exclusiva (DE), e todos os professores temporários/ substitutos têm carga horária de 40h.

${ }^{2}$ Valor relacionado ao Salário Mínimo Nacional (R\$ 724,00 ou \$ 290,76, com cotação dólar comercial do dia 
5 a 6 salários $\quad 5 \quad 5 \quad 25,0$

7 a 8 salários $\quad 3 \quad 15,0$

Acima de 8 salários $\quad 12 \quad 60,0$

Fonte: Elaborado pelos autores, 2015

Os dados da Tabela 1 revelam o predomínio de professores do gênero masculino (65\%), uma maior concentração de professores com idade igual ou superior a 50 anos $(40 \%)$ e entre 30-39 anos (30\%), naturais da cidade de Pelotas - RS (55\%). Constata-se ainda a prevalência do estado civil casado (75\%).

Um dado importante em relação ao perfil sociodemográfico dos professores dessa rede de ensino se faz em relação ao gênero, em que o resultado deste estudo de $65 \%$ do gênero masculino se contrapõe ao perfil "típico" do professor brasileiro, $71 \%$ feminino, de acordo com a Pesquisa Internacional sobre Ensino e Aprendizagem (Teaching and Learning International Survey - TALIS), realizada pela Organização para a Cooperação e Desenvolvimento Econômico (OCDE) e coordenada no Brasil pelo Instituto Nacional de Estudos e Pesquisas Educacionais (INEP) em 2104 (BRASIL, 2014). Outras pesquisas específicas com professores de EF também revelaram o predomínio do gênero feminino (SINOTT, 2014; MARIN et al., 2010; LEMOS; NASCIMENTO; BORGATTO, 2007; IAOCHITE et al., 2011; BOTH; NASCIMENTO; BORGATTO, 2008).

De acordo com os dados da mesma tabela, os docentes dessa rede, em sua maioria, atuam no campus Pelotas (80\%), são efetivos (85\%), com jornada de trabalho de $40 \mathrm{~h}$ e regime de dedicação exclusiva ( $85 \%)$, ocupando somente a função docente $(90 \%)$ e com remuneração acima de 8 salários mínimos (60\%). Apenas dois professores (10\%) acumulam funções docente e administrativa, sendo estas as de coordenadores da área de EF de cada campus.

No que concerne às instituições de formação inicial dos professores dessa investigação, a esfera pública constituiu a maioria (85\%). Já quanto à titulação, observa-se que a maior parte dos docentes tem o nível de pós-graduação lato sensu ou stricto sensu de mestrado (45\% ambos), e o restante (10\%) tem a titulação de doutor.

Quando à realização de atividades remuneradas antes do exercício da docência no IFSUL, os questionados citaram principalmente atividades ligadas ao ambiente escolar, como docente de outras redes de ensino e em diferentes níveis, bem como coordenação de atividades extracurriculares ou de núcleos esportivos. Foram também citadas atividades relacionadas ao ambiente não escolar como personal trainer, treinador de futsal/futebol, proprietário de empresa de organização de eventos e arbitragens e proprietário/professor de academia. A única citação não relacionada à EF foi a de comerciante, sendo que um único participante da pesquisa citou não exercer atividade remunerada antes de ser professor de EF nos campi objeto desta pesquisa.

Dentre os professores que trabalham em outro local ou exercem outra(s) atividade(s) remunerada(s), duas respostas estão relacionadas à educação: na função de professor em outra rede de ensino e servidor na Secretaria de Educação e Desporto Municipal; e outras duas citações estão relacionadas com o ambiente não escolar: árbitro de futebol e profissional em academia de ginástica.

Descrito o perfil sociodemográfico dos participantes da pesquisa, partimos então para as questões que buscaram investigar a satisfação profissional dos professores de EF da RFEPCT na cidade de Pelotas - RS.

Na Tabela 2, estão apresentadas as respostas das questões fechadas referentes à categoria Exercício da Profissão, que propôs averiguar a satisfação profissional nas dimensões: condições de trabalho, remuneração, jornada de trabalho e relações hierárquicas. Além disso,

2/10/2014 de \$ 2,49). Fonte:< http://economia.uol.com.br/cotacoes/>. 
procurou-se avaliar também a satisfação relacionada ao Trabalho Pedagógico, referindo-se a questões relacionadas diretamente com a prática profissional dos professores, a saber: distribuição das aulas, conteúdos e o envolvimento dos alunos nas aulas de EF.

Tabela 2. Indicadores de satisfação dos professores relacionados ao exercício da profissão e ao trabalho pedagógico

\begin{tabular}{|c|c|c|c|c|c|}
\hline $\begin{array}{l}\text { Indicadores de } \\
\text { satisfação }\end{array}$ & $\begin{array}{c}\text { Plenamente } \\
\text { Satisfeito } \\
\text { n }(\%)\end{array}$ & $\begin{array}{l}\text { Satisfeito } \\
\text { n }(\%)\end{array}$ & $\begin{array}{c}\text { Razoavelmen- } \\
\text { te Satisfeito } \\
\text { n }(\%)\end{array}$ & $\begin{array}{c}\text { Pouco } \\
\text { Satisfeito } \\
\text { n }(\%) \\
\end{array}$ & $\begin{array}{c}\text { Insatisfei- } \\
\text { to } \\
\text { n }(\%) \\
\end{array}$ \\
\hline \multicolumn{6}{|c|}{ Categoria 1 - Exercício da profissão } \\
\hline $\begin{array}{l}\text { Condições de } \\
\text { trabalho }\end{array}$ & $13(65,0)$ & $3(15,0)$ & $0(0,0)$ & $4(20,0)$ & $0(0,0)$ \\
\hline Remuneração & $9(45,0)$ & $7(35,0)$ & $3(15,0)$ & $0(0,0)$ & $1(5,0)$ \\
\hline $\begin{array}{l}\text { Jornada de traba- } \\
\text { lho }\end{array}$ & $15(75,0)$ & $3(15,0)$ & $1(5,0)$ & $0(0,0)$ & $1(5,0)$ \\
\hline $\begin{array}{l}\text { Relações hierár- } \\
\text { quicas }\end{array}$ & $4(20,0)$ & $13(65,0)$ & $2(10,0)$ & $1(5,0)$ & $0(0,0)$ \\
\hline $\begin{array}{c}\text { Geral da catego- } \\
\text { ria }\end{array}$ & $41(51,3)$ & $26(32,5)$ & $6(7,5)$ & $5(6,2)$ & $2(2,5)$ \\
\hline \multicolumn{6}{|c|}{ Categoria 2 - Trabalho Pedagógico } \\
\hline $\begin{array}{c}\text { Distribuição das } \\
\text { aulas }\end{array}$ & $14(70,0)$ & $2(10,0)$ & $2(10,0)$ & $1(5,0)$ & $1(5,0)$ \\
\hline Conteúdos & $4(20,0)$ & $14(70,0)$ & $2(10,0)$ & $0(0,0)$ & $0(0,0)$ \\
\hline $\begin{array}{l}\text { Envolvimento dos } \\
\text { alunos }\end{array}$ & $5(25,0)$ & $12(60,0)$ & $3(15,0)$ & $0(0,0)$ & $0(0,0)$ \\
\hline $\begin{array}{l}\text { Geral da catego- } \\
\text { ria }\end{array}$ & $23(38,2)$ & $28(46,7)$ & $7(11,7)$ & $1(1,7)$ & $1(1,7)$ \\
\hline
\end{tabular}

Fonte: Elaborado pelos autores, 2015.

Do total das 80 respostas dos participantes, em relação à categoria Exercício da Profissão, a alternativa Plenamente satisfeito foi a mais assinalada, com 41 respostas $(51,3 \%)$; a opção Satisfeito obteve 26 marcações (32,5\%); Razoavelmente satisfeito, 6 (7,5\%); Pouco satisfeito, 5 (6,2\%); e a opção Insatisfeito foi assinalada apenas 2 vezes $(2,5 \%)$.

Além disso, das 60 respostas da categoria Trabalho Pedagógico, a alternativa Plenamente satisfeito obteve 23 marcações (38,2\%); a opção Satisfeito, 28 (46,7\%); Razoavelmente satisfeito, 7 marcações $(11,7 \%)$; Pouco satisfeito, apenas 1 marcação $(1,7 \%)$; assim como a alternativa Insatisfeito, com também 1 marcação $(1,7 \%)$.

A Tabela 3 mostra as respostas dos docentes referentes à última questão fechada do questionário, na qual foram indagados sobre sua satisfação geral com a profissão.

Tabela 3. Índice de satisfação geral com a profissão

\begin{tabular}{lcc}
\hline Indicadores de satisfação & $\mathbf{N}$ & \% \\
\hline Plenamente satisfeito & 12 & 60,0 \\
Satisfeito & 7 & 35,0 \\
Razoavelmente satisfeito & 1 & 5,0 \\
Pouco satisfeito & 0 & 0,0 \\
Insatisfeito & 0 & 0,0 \\
\hline Total & 20 & 100,0 \\
\hline
\end{tabular}

Fonte: Elaborado pelos autores, 2015 
De acordo com a Tabela 3, referente à satisfação geral com a profissão, a marcação Plenamente satisfeito foi assinalada por 12 professores (60\%), a opção Satisfeito foi assinalada por 7 professores (35\%), e um professor (5\%) assinalou a opção Razoavelmente satisfeito. As opções Pouco satisfeito e Insatisfeito não foram assinaladas por nenhum professor.

Os resultados encontrados nesta investigação, através de questões referentes ao Exercício da Profissão e ao Trabalho Pedagógico, além da satisfação geral com a profissão, são superiores em relação à satisfação docente aos achados no estudo de Both, Nascimento e Borgatto (2008), realizado com 580 docentes efetivos de EF do magistério público estadual de Santa Catarina (SC), em que, através da Escala de Avaliação da Qualidade de Vida no Trabalho Percebida, os autores encontraram um índice de $14,1 \%$ de satisfação no componente remuneração/compensação; $35,7 \%$ nas condições de trabalho e de $81 \%$ na organização do trabalho.

Com a mesma metodologia do estudo anterior, o estudo de Lemos, Nascimento e Borgatto (2007), com 380 professores de EF do Ensino Fundamental e Médio do Magistério Público Estadual do RS, detectou índices de satisfação de apenas 10,5\% no item remuneração/compensação; $40 \%$ nas condições de trabalho e 76,6\% na organização do trabalho.

Já o estudo de Iaochite et al. (2011), do qual participaram 220 professores de EF de escolas públicas e privadas da região de Campinas e do Vale do Paraíba, no estado de São Paulo, por meio da Escala de Autoeficácia de Professores de EF (POLYDORO et al., 2004), verificou que $15,5 \%$ desses professores estão em um nível muito alto e outros $40,8 \%$ em um nível alto em relação à avaliação da satisfação pessoal com a docência.

Outro estudo, de Righeto (2009), investigou o nível de satisfação profissional de 34 professores de EF da rede pública estadual de Florianópolis - SC, atuantes no ensino fundamental, através do Questionário de Satisfação no Trabalho (QVT S20/23), e verificou que apenas 8,8\% deles encontram-se satisfeitos na dimensão remuneração; 29,4\% de satisfação referente às relações pessoais nas instâncias de poder, constatando ainda que $67,6 \%$ dos professores encontram-se satisfeitos no quesito trabalho como fonte de realização pessoal.

A pesquisa de Justino (2011) analisou o nível de satisfação dos professores de EF escolar na cidade de Carmo do Rio Claro - MG, diagnosticando que somente 15,3\% estão totalmente satisfeitos com a profissão e outros $46,2 \%$ encontram-se satisfeitos. Já no quesito local de trabalho, $46,2 \%$ estão satisfeitos e, no que se refere aos alunos, $15,5 \%$ dos docentes encontram-se totalmente satisfeitos e outros $53,9 \%$ estão satisfeitos. No tocante à remuneração, constatou-se que apenas 7,7\% estão satisfeitos e, em relação à jornada de trabalho, 15,3\% estão totalmente satisfeitos e outros $46,2 \%$ encontram-se satisfeitos.

Os baixos índices de insatisfação identificados através das alternativas Pouco satisfeito ou Insatisfeito deste estudo estão relacionados principalmente com componentes que não dependem exclusivamente da ação docente, mas dos gestores públicos, como condições de trabalho (infraestrutura, materiais, espaço físico, entre outras) e remuneração, bem como de instâncias locais, como no componente distribuição das aulas.

Os docentes ainda foram questionados sob a forma de questões abertas, que eram relacionadas a sua satisfação ou insatisfação profissional, nas quais buscamos averiguar quais os principais aspectos que levam a um ou a outro índice.

Quanto à satisfação dos docentes, alguns motivos como a relação estabelecida com os alunos mediante o reconhecimento do trabalho realizado enquanto docentes são aspectos positivos nesse contexto. Para os docentes entrevistados, o papel desempenhado como professor pode significar algo importante na vida dos alunos, uma vez que buscam incentivá-los a estabelecer metas ou objetivos no decorrer de sua vida.

Tal reconhecimento pode ser percebido no depoimento de um dos docentes, quando fala a respeito do "reconhecimento pessoal dos alunos que passam pela gente. É muito legal a 
relação que nós desenvolvemos nas aulas de EF e nos desportos. Nada paga tu encontrares um aluno após vários anos e ouvi-lo dizer que sente saudade de nossas aulas" (Professor H).

Outros motivos elencados como fatores preponderantes para a obtenção da satisfação profissional: a boa remuneração proporcionada pela atividade, as condições de infraestrutura das instituições em que estão inseridos, o comprometimento dos alunos e, ainda, o gosto pela prática docente. Percebe-se que os principais motivos de satisfação profissional também se relacionam com a escolha da profissão, seja a relação com os esportes e atividade física, seja o relacionamento com os alunos/equipes escolares ou a própria identificação com a docência.

Esses sentimentos de satisfação corroboram outros estudos que detectaram a convivência, a afetividade e o aprendizado dos alunos como maior motivo de satisfação docente (JUSTINO, 2011; SILVA; KRUG, 2007; MOREIRA, 2010).

Em contrapartida, os professores responderam sobre os principais motivos que os levavam a ter insatisfação profissional: a baixa valorização profissional, seja da valorização da função, seja de reconhecimento da área ou de nível salarial, principalmente em relação a colegas de outras redes de ensino, foi o elemento mais citado. Notamos, então, que existe uma questão institucional que interfere na percepção da satisfação dos docentes, mesmo que a relação com os alunos seja um aspecto positivo bastante ressaltado. Ainda quanto ao reconhecimento, para um dos docentes:

De forma mais ampla me causa insatisfação saber que outros tantos colegas de profissão não têm as mesmas condições de trabalho que eu. Condições de trabalho entendam-se como estruturas físicas, materiais, incentivos à qualificação, excessiva carga horária de trabalho, baixa remuneração entre outros (Professor U).

Para outro professor, "a remuneração que, apesar de ser uma das melhores da profissão, geralmente fica defasada em relação a outros bens de consumo, como educação e alimentação" (Professor N).

Também a infraestrutura, apesar de ter uma diferença significativa quando comparada às escolas de Educação Básica da cidade, foi um aspecto que igualmente esteve atrelado à insatisfação profissional, juntamente com o reconhecimento da área de EF, pois, em alguns locais, a infraestrutura (área física e equipamentos) ainda é deficitária para o trabalho do professor, como é o caso de uma das instituições pesquisadas, visto que existem ainda necessidades estruturais e materiais a serem supridas. Além disso, o reconhecimento da área de EF ainda necessita ser maior, segundo as respostas dos docentes.

De acordo com Iaochite et al. (2011) e Krug e De Bastos (2002), os professores de EF normalmente têm de lidar com dificuldades referentes à questão de materiais e infraestrutura, além de aspectos ligados ao planejamento e à administração das aulas.

Foi possível perceber que, muitas vezes, segundo os professores, existe uma "frustração do não poder fazer as coisas, como, por exemplo, levar os alunos aos jogos ' $\mathrm{x}$ ', mas a escola não libera ou não tem transporte" (Professor Q). Ou seja, existe uma mobilização dos docentes para a participação em atividades diferenciadas, mas o apoio institucional não é o mais adequado, deixando os professores com um sentimento de insatisfação quanto ao seu trabalho.

Também as relações estabelecidas junto aos colegas no ambiente de trabalho foi um fator citado pelos professores relacionado à insatisfação profissional, pois, segundo eles, "existe descaso de colegas frente à profissão" (Professor K) e ainda é possível "ver alguns profissionais/colegas pouco comprometidos com suas aulas" (Professor L), além de existirem problemas "na forma como acontecem as relações de poder, a falta de sinceridade nas relações pessoais e o individualismo" (Professor T).

Sobre as relações sociais que se estabelecem no âmbito escolar, Krug (2011) infere que condicionantes sociais atuam sobre a escola, tanto condicionantes internos como condici- 
onantes externos às instituições escolares. No estudo de Bertini Júnior e Tassoni (2013), os autores identificaram que as mudanças ocorridas na área de EF influenciaram as condições de trabalho na escola e a forma de organizar a prática pedagógica, influenciando na valorização da área, bem como do docente,

Ainda sobre a insatisfação no trabalho de professores de EF, Justino (2011) e Silva e Krug (2007) apontaram como fatores geradores de insatisfação a desvalorização da EF, a falta de condições físicas ou materiais e a remuneração, ou seja, fatores externos à ação dos professores, mas que acabam por interferir em sua prática pedagógica. Outro estudo, de Moreira (2010), acrescenta, ainda, como sentimentos de insatisfação a extensa carga horária, a indisciplina e a falta de interesse dos alunos, sentimentos estes que neste estudo apresentaram níveis baixos de insatisfação nas dimensões jornada de trabalho, remuneração e envolvimento dos alunos.

Em nossa análise geral, os motivos de insatisfação elencados pelos professores vão ao encontro ao estudo de Bueno e Lapo (2003), que examinaram a questão do abandono do magistério público na rede de ensino do estado de São Paulo e verificaram que, além dos baixos salários, as precárias situações e o desprestígio profissional estão entre os fatores que mais contribuem para que eles deixem a profissão docente.

Nesta direção, estudos revelaram que devido às especificidades da classe docente, muitos professores são acometidos pela Síndrome de Burnout (CARLOTTO, 2002; SANTINI; MOLINA NETO, 2005; SINOTT et al., 2014; VALÉRIO; AMORIM; MOSER, 2009), sendo que os professores de EF apresentam menor índice devido às condições ambientais de suas aulas e à maior prática de atividades físicas (VALÉRIO; AMORIM; MOSER, 2009). É importante ressaltar que as dimensões que identificam a Síndrome de Burnout - exaustão emocional, despersonalização e realização profissional - são geradas também a partir da insatisfação dos professores em relação a sua profissão.

\section{Considerações finais}

O objetivo deste trabalho foi verificar a satisfação profissional dos professores de EF da RFEPCT na cidade de Pelotas - RS. Além disso, verificou o perfil sociodemográfico dos professores de EF dessa rede de ensino.

Em relação ao perfil sociodemográfico desses professores, os resultados confirmam a realidade do sistema educacional brasileiro, de ordem seletiva e excludente, pois, se relacionarmos gênero e remuneração dos professores ao longo das diferentes etapas da Educação Básica com a Rede Federal de Ensino e a Educação Superior, teremos nas redes de ensino da Educação Básica, onde estão os menores salários e as piores condições de trabalho, o gênero feminino prevalecendo. Já na Rede Federal de Ensino e na Educação Superior, redes estas em que se concentram os melhores salários e condições de trabalho, o quadro inverte-se e o gênero masculino prevalece. Outros resultados que merecem considerações dizem respeito à prevalência das Instituições Públicas de Ensino nas formações iniciais dos docentes desta rede e o regime de trabalho de dedicação exclusiva. Em relação à formação inicial em sua maioria em instituições públicas, este fato contrapõe-se à predominância do ensino privado na Educação Superior brasileira. E, referente ao regime de trabalho de dedicação exclusiva, este provoca a melhoria do salário e evita situações de multiemprego, de elevada carga horária, ou mesmo a necessidade de ter de exercer outras atividades laborais fora do âmbito escolar, como forma de melhorar a remuneração, o que é comum com professores de outras redes de ensino.

A categoria Exercício da Profissão, nas dimensões condições de trabalho, remuneração, jornada de trabalho e relações hierárquicas, e a categoria Trabalho Pedagógico, nas di- 
mensões distribuição das aulas, conteúdos e envolvimento dos alunos nas aulas, bem como a satisfação geral com a profissão, apresentaram índices de satisfação altos.

Os baixos índices de insatisfação identificados neste estudo estão relacionados principalmente com componentes que não dependem exclusivamente da ação docente, porém interferem em sua prática pedagógica, como infraestrutura e relações hierárquicas.

Os principais sentimentos de satisfação elencados foram a relação estabelecida com os alunos e o seu reconhecimento por parte destes, além da realização profissional e pessoal de ser professor. Em contrapartida, a pouca valorização e o reconhecimento da profissão e da área por outros membros da comunidade escolar e esferas gestoras da educação foram as razões da insatisfação. Fatos esses que comprovam ser a escola um local de relações e de aprendizagem social. Além disso, os discursos dos professores confirmaram suas respostas assinaladas no questionário.

Considerando as evidências identificadas nesta pesquisa, concluímos que os professores de EF do campus Pelotas e do campus Visconde da Graça, pertencentes a essa rede de ensino, encontram-se em um nível de satisfação relativamente alto em relação ao exercício da profissão docente.

Desta forma, a Rede Federal de Ensino constitui-se uma opção de superação diante dos processos de intensificação e precarização do trabalho docente tão presente nas demais redes de ensino públicas, conforme mostram os estudos com os quais se dialogou nesta pesquisa. Consideramos necessário que outros estudos desta natureza sejam realizados futuramente, dada a relevância da profissão docente, principalmente em campi novos e em processo de implantação dessa rede de ensino.

\title{
SATISFACTION WITH THE PROFESSION: A STUDY WITH PHYSICAL EDUCA- TION TEACHERS
}

\begin{abstract}
The objective of this study was to verify the professional satisfaction of the EF teachers of the Federal Teaching Network in the city of Pelotas, RS. This is a descriptive case study that used a questionnaire regarding satisfaction with the profession and the teaching profile. The total number of EF teachers $(n=20)$ participated in the study. In both categories, Exercise of the Profession and Pedagogical Work, were found high levels of satisfaction and more than 90\% of teachers are satisfied with the profession. The exchanges established with the students, the recognition by them and the professional achievement were the main reasons for this. External factors such as low valuation and little recognition by peers or institutional management were reasons for teachers' dissatisfaction.
\end{abstract}

Keywords: Teachers. Physical Education. Job satisfaction.

\section{SATISFACCIÓN CON LA PROFESIÓN: UN ESTUDIO CON PROFESORES DE EDUCACIÓN FÍSICA}

\section{Resumen}

El trabajo tuvo como objetivo verificar la satisfacción profesional de los profesores de EF de la Red Federal de Enseñanza en la ciudad de Pelotas-RS. Se trata de un estudio de caso descriptivo que utilizó un cuestionario relativo a la satisfacción con la profesión y el perfil docente. Participaron del estudio la totalidad de los profesores de EF $(n=20)$. Tanto en la categoría Ejercicio de la profesión y como en la categoría Trabajo pedagógico se encontraron niveles elevados de satisfacción y más del $90 \%$ de los profesores está satisfecho con la profesión. Los 
intercambios establecidos con los alumnos, el reconocimiento por parte de ellos y la realización profesional fueron los principales motivos para ello. Factores externos como la baja valorización y el poco reconocimiento por los colegas o la gestión institucional fueron razones para la insatisfacción de los profesores.

Palabras clave: Profesores. Educación Física. Satisfacción en el trabajo.

\section{Referências}

ACIOLY, P. L. Estilo de vida e insatisfação referida quanto ao trabalho entre professores de Educação Física de Florianópolis. 2005. 94f. Dissertação (Mestrado em Saúde Pública) - Centro de Ciências da Saúde, Universidade Federal de Santa Catarina, Florianópolis, 2005 .

AZEVEDO, E. S. O agir pedagógico dos professores de educação física no ensino técnico federal do estado do Rio Grande do Sul. Dissertação (Mestrado em Educação Física) Centro de Desportos, Programa de Pós-Graduação em Educação Física, Universidade Federal de Santa Catarina, Florianópolis, 2001.

AZEVEDO, E. S.; PEREIRA, B. O.; SÁ, C. A. Percepções docentes acerca da formação inicial na atuação pedagógica: estudo de caso dos professores de educação física. Revista IberoAmericana de Educação, n. 56, p. 201-226, 2011.

BARDIN, L. Análise de conteúdo. São Paulo: Edições 70, 2011.

BERTINI JUNIOR, N.; TASSONI, E. C. M. A Educação Física, o docente e a escola: concepções e práticas pedagógicas. Revista Brasileira de Educação Física e Esporte, v. 27, n. 3, p. 467-483, 2013.

BORGES, S. C. M. L.; SIMÕES, D. S. Satisfação profissional e saúde mental: um estudo empírico com uma amostra de docentes do ensino superior. Internacional Journal of Development and Education Psychology, v. 4, n. 1, 2012.

BOTH, J.; NASCIMENTO, J. V.; BORGATTO, A. F. Percepção da qualidade de vida no trabalho e perfil do estilo de vida dos docentes de Educação Física do estado de Santa Catarina. Revista da Educação Física/UEM, v. 19, n. 3, 2008.

BRASIL. Lei $n^{\circ}$. 11.892, de 29 de dezembro de 2008. Institui a Rede Federal de Educação Profissional, Científica e Tecnológica, cria os Institutos Federais de Educação, Ciência e Tecnologia, e dá outras providências, 2012.

BRASIL. Ministério da Educação e Cultura. Pesquisa internacional revela perfil de professor e diretor. 2014. Disponível em: $<$ http://portal.mec.gov.br/index.php?option=com_content \&view=article\&id=20550:pesquisainternacional-revela-perfil-de-professor-e-diretor\&catid=211\&Itemid=164>. Acesso em: 26 jun. 2015.

BUENO, B. O.; LAPO, F. R. Professores, desencanto com a profissão e abandono do magistério. Caderno de Pesquisa-USP, v. 118, p. 65-88, 2003. 
CARLOTTO, M. S.. A síndrome de Burnout e o trabalho docente. Psicologia em estudo, v. 7, n. 1, p. 21-29, 2002.

CATAPAN, A. et al. Qualidade de vida no trabalho (QVT): uma análise com professores do Ensino Médio e Superior do Brasil. Revista Brasileira de Qualidade de Vida, v. 6, n. 2, abr./jun., 2014.

COLARES, M. C. et al. Indicadores de qualidade de vida em professores: uma revisão sistemática de estudos descritivos. Pensar a prática, v. 18, n. 3, jul./set., 2015.

FARIAS, G. O. et al. Carreira docente em Educação Física: uma abordagem sobre a qualidade de vida no trabalho de professores da rede estadual de ensino do Rio Grande do Sul. Revista Educação Física/UEM. v. 19, n. 1, 2008.

FERREIRA, A. C. M. Satisfação no trabalho de docentes de uma Instituição Pública de Ensino Superior: reflexos na qualidade de vida. 2011. 126f. Dissertação (Mestrado em Enfermagem) - Programa de Pós-Graduação em Enfermagem da Faculdade de Enfermagem da Universidade Federal de Goiás, Goiás, 2011.

GIL, A. C. Como elaborar projetos de pesquisa. São Paulo: Atlas, 2002

GOMES, A. R. et al. Stress, avaliação cognitiva e Burnout: um estudo com professores do ensino superior. Revista Sul Americana de Psicologia, v. 1, n. 1, 2013.

IAOCHITE, R. T. et al. Autoeficácia docente, satisfação e disposição para continuar na docência por professores de Educação Física. Revista Brasileira de Ciências do Esporte, v. 33, n. 4, 2011.

JUSTINO, F. H. Nível de satisfação dos professores de Educação Física Escolar da Cidade de Carmo do Rio Claro - MG. 2011. 47 f. Trabalho de Conclusão de Curso (Licenciatura em Educação Física) - Instituto Federal de Educação, Ciência e Tecnologia do Sul de Minas Gerais, Muzambinho, 2011.

KRUG, H. N.; DE BASTOS, F. da P. A construção do conhecimento prático do professor de Educação Física: um estudo de caso etnográfico. Revista do Centro de Educação, v. 27, n. $2,2002$.

KRUG, H. N. O percurso da vida escolar básica e a relação com a escolha profissional dos acadêmicos da Licenciatura em Educação Física da Universidade Federal de Santa Maria. Revista Digital Lecturas: Educación Física y Deportes, Buenos Aires, v.14, p. 1-10, 2010.

KLIJN, T. M. P. Satisfação no trabalho de mulheres acadêmicas da Universidade de Concepción, Chile. 1998. 271f. Tese (Doutorado em Enfermagem em Saúde Pública) - Escola de Enfermagem de Ribeirão Preto da Universidade de São Paulo, 1998.

LEMOS, C. A. F.; NASCIMENTO, J. V.; BORGATTO, A. F. Parâmetros individuais e socioambientais da qualidade de vida percebida na carreira docente em Educação Física. Revista Brasileira de Educação Física e Esporte, v. 21, n. 2, 2007. 
MARIN, E. C. et al. Educação Física no contexto rural: perfil dos professores e prática pedagógica. Revista Brasileira de Ciências do Esporte, v. 31, n. 2, 2010.

MARQUEZE, E. C.; MORENO, C. R. C. Satisfação no trabalho - uma breve revisão. Revista Brasileira de Saúde Ocupacional. v.30, n.112, jul./dez. 2005.

MARTINEZ, M. C.; PARAGUAY, A. I. B. B. Satisfação e saúde no trabalho: aspectos conceituais e metodológicos. Cadernos de psicologia social do trabalho, v. 6, 2003.

MEIRELES, C. M. S. Das artes e officios à educação tecnológica: 90 anos de história... Pelotas: Editora da UFPEL, 2007.

MOREIRA, H. R. et al. Qualidade de vida no trabalho e síndrome de Burnout em professores de Educação Física do estado do Rio Grande do Sul, Brasil. Revista Brasileira de Atividade Física \& Saúde, v. 14, n. 2, 2012.

MOREIRA, S. Professor de Educação Física: Estás satisfeito com tua profissão? 2010. 29 f. Trabalho de Conclusão de Curso (Licenciado em Educação Física) - Escola Superior de Educação Física, Universidade Federal de Pelotas, Pelotas, 2010.

NÓVOA, A. Os professores: quem são? donde vêm? para onde vão? In: STOER, S.R. (Org.). Educação, ciências sociais e realidade portuguesa: uma abordagem pluridisciplinar. Porto: Afrontamento, 1991.

ORGANIZAÇÃO INTERNACIONAL DO TRABALHO (OIT). Emploi et conditions de travail des enseignements. Genève: Bureau International du Travail des Enseignants, 1981.

PEDRO, N.; PEIXOTO, F. Satisfação profissional e auto-estima em professores dos $2^{\circ}$ e $3^{\circ}$ ciclos do Ensino Básico. Análise Psicológica, v. 24, n. 2, 2006.

PEREIRA, E. F.; TEIXEIRA, C. S.; LOPES, A. S. Qualidade de vida de professores de Educação Básica do município de Florianópolis, SC, Brasil. Ciência \& Saúde Coletiva, v. 18, n. 7, 2013.

POLYDORO, S. et al. Escala de auto-eficácia docente em educação física. In: MACHADO C. (Org.). Avaliação psicológica: formas e contextos. Braga: Psiquilíbrios, 2004.

RIGHETO, C. B. Satisfação profissional dos professores de Educação Física da rede pública estadual de Florianópolis. 2009. 18 f. Trabalho de Conclusão de Curso (licenciatura em Educação Física) - Centro de Ciências da Saúde e do Esporte, Universidade Federal de Santa Catariana, Florianópolis, 2009.

SANTINI, J.; MOLINA NETO, V. A síndrome do esgotamento profissional em professores de Educação Física: um estudo na rede municipal de ensino de Porto Alegre. Revista Brasileira de Educação Física e Esporte, São Paulo, v.19, n. 3, p. 209-222, jul./set., 2005.

SCHWARTZMAN, S.; CASTRO, C. M. Ensino, formação profissional e a questão da mão de obra. Ensaio: avaliação e políticas públicas em Educação, v. 21, n. 80, jul./set., 2013. 
SECO, G. M. S. B. A Satisfação dos professores: algumas implicações práticas para os modelos de desenvolvimento profissional docente. Educação \& Comunicação, n.8, p. 73- 92, jan. 2005.

SILVA, M. S.; KRUG, H. N. Os sentimentos satisfação e insatisfação dos professores de Educação Física. Revista Digital Buenos Aires, ano 12, n. 115, p. s/n, 2007.

SINOTT, E. C. et al. Síndrome de Burnout: um estudo com professores de Educação Física. Movimento (ESEF/UFRGS), v. 20, n. 2, p. 519-539, 2014.

TAVARES, M. G. Evolução da rede federal de educação profissional e tecnológica: as etapas históricas da educação profissional no Brasil. In: IX ANPED-SUL: SEMINÁRIO DE PESQUISA EM EDUCAÇÃO DA REGIÃO SUL. Anais... Florianópolis, v. 9, 2012.

THOMAS, J. R.; NELSON, J. K.; SILVERMAN, S. J. Métodos de pesquisa em atividade física. Porto Alegre: Artmed. 2007.

TRIVIÑOS, A. N. S. Introdução à pesquisa em ciências sociais: a pesquisa qualitativa em educação. São Paulo: Atlas, 1987.

VALÉRIO, F. J.; AMORIM, C.; MOSER, A. M. A síndrome de Burnout em professores de Educação Física. Revista de Psicologia da IMED, v. 1, n. 1, 2009.

Recebido em: 13/01/2016

Revisado em: 09/10/2017

Aprovado em: 26/11/2017

Endereço para correspondência:

ivanbremmoliveira@gmail.com

Ivan Bremm De Oliveira

Universidade Federal de Pelotas, Escola Superior de Educação Física

Rua Luís de Camões, 625

Três Vendas

96055-630 - Pelotas, RS - Brasil 